
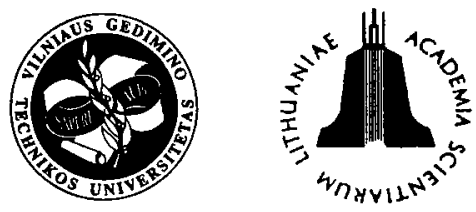

JOURNAL OF CIVIL ENGINEERING AND
$\mathrm{http}: / \mathrm{www} . v \mathrm{vtu} . \mathrm{lt} / \mathrm{english} / \mathrm{editions}$

2002, Vol VIII, No 3, 177--183

\title{
NON-LINEAR ANALYSIS OF PLANE STEEL PRESTRESSED TRUSS IN FIRE
}

\author{
Pawel Fedczuk, Wojciech Skowroński ${ }^{1}$ \\ Faculty of Civil Engineering, Technical University of Opole, ul. Katowicka 48, 45-061 Opole, Poland. \\ ${ }^{1}$ E-mail: wskow@po.opole.pl
}

Received 01 June 2001; accepted 05 Febr 2002

\begin{abstract}
The concept of analysis of 2-D static loaded prestressed steel trusses till failure during fire using a modified method of forces is presented. Failure of steel trusses in fire is based on the criterion of stresses. Behaviour of steel is described by non-linear constitutive model (based on hypo-elastic Ramberg-Osgood formula and Dorn creep theory) and Plem proposition (for string). Both models are approximated in calculations by hyperbolic Norton-Bailey rule. Fire simulates thermal force as an action of high temperature that increases linearly up to some level.

The complete formulation of this method is illustrated by the algorithm of model parameters identification. Analysis of results for specific prestressed truss made of ASTM A36 and A421 steel in fire is presented.
\end{abstract}

Keywords: fire, steel, truss, creep theory, non-linear constitutive model.

\section{Introduction}

In various laboratories throughout the world the fire tests of building structures have been made for years. Demand for this research is great and results from the restrictions concerning safety in modern building as well as from the necessity of testing a new, better and cheaper fire prevention for structures, in particular, for the steel ones. Results of fire tests determine the reaction of an element separated from building construction and heated in accordance with a standard.

Fire tests of steel trusses are expensive (cost of fabrication, equipment and maintenance of a testing furnace, cost of manufacture of samples and of experiments) and complicated. That is why some substitute calculating methods are developed. The paper presents the concept of analysis of 2-D static loaded steel truss (with string) till failure during fire by using a modified method of forces $[1,2]$.

Failure of the steel trusses in fire is based on the criterion of stresses. Behaviour of steel is described by non-linear constitutive model [3] (based on hypo-elastic Ramberg-Osgood formula and Dorn creep theory) and Plem proposition [4] (for string). Both models are approximated in calculations by hyperbolic Norton-Bailey rule. Fire simulates thermal forcing being an action of high temperature that increases linearly up to some level.

The complete formulation of this method contains presentation of calculation algorithm with two-stage method of model parameters identification [5]. Analysis of results for specific prestressed truss made of ASTM A36 and A421 steel in fire is presented.

\section{Models of steel}

Increase in temperature causes essential changes in the structural steel properties. The proportional limit and the yield stress of steel decrease monotonically with the gain in temperature whereas the strength grows with an increasing temperature up to about $250^{\circ} \mathrm{C}$ and then drops rapidly. Cold-drawn steels lose their strength at elevated temperatures faster than mild steel. Elasticity modulus of steel decreases at elevated temperatures but, as it was observed, it decreases slower than the yield stress. At elevated temperatures, steel strains due to creep can be considerable.

Total structural steel strains at elevated temperatures are obtained as a sum of thermal strains and mechanical strains described by the equation of Ramberg-Osgood and time-dependent strains (thermal creep strains) according to Dorn theory $[3,6]$ :

$$
\begin{gathered}
\varepsilon_{T}=\psi(T)=\varepsilon_{T}+\sigma \psi_{1}(T)+\sigma \sigma^{\mu(T)-1} \psi_{2}(T) \\
+\sigma \sigma^{m-1} \psi_{3}\left(T^{\prime}, t\right)=\varepsilon_{T}+\sigma_{\mathrm{E}(T)}^{1}+\sigma \sigma^{\mu(T)-1} \\
0.002 \\
\left.\left[\sigma_{y}(T)\right]^{\mu(T)}+\sigma \sigma^{m-1} B\left[\begin{array}{c}
1 \\
\int \exp \left(-\frac{\Delta H}{\mathrm{R} T}\right) \\
0
\end{array}\right)\right]^{13} .
\end{gathered}
$$

$\varepsilon$ - denotes strain, $\sigma$ - stress, $\Delta H$ - activation energy of creep, $R=8,3183$ - gas constant, Joule/moleK, $B$ and $m$ - material constants, $t$ - time, $\min , T$ - temperature, ${ }^{\circ} \mathrm{C}$, $T^{\prime}$ - temperature, K. Young's modulus $E(T)$, yield stress $\sigma_{y}(T)$, strain-hardening coefficient $\mu(T)$ and material constants $\psi_{1}, \psi_{2}, \psi_{3}$ - are temperature dependent. 
The model was worked out under the following assumptions [7]:

1) steel is a homogeneous and isotropic continuum,

2) no repeated load is considered,

3) the strain process is slow or is a static one,

4) strains are small.

Total prestressing steel strain (string) at elevated temperature is obtained as a sum of thermal strains and strains described by the equation of Plem [4]

$$
\begin{gathered}
\varepsilon(\sigma, T)=\varepsilon * T+\varepsilon_{\mathrm{o}}\left[2 \sqrt{Z(\sigma) \theta} \begin{array}{c}
\varepsilon_{\mathrm{o}}
\end{array}\right] \text { for } 0 \leq \theta \leq \theta_{\mathrm{o}}, \\
\varepsilon(\sigma, T)=\varepsilon^{*} T+\varepsilon_{\mathrm{o}}\left[\begin{array}{c}
Z(\sigma) \theta \\
\varepsilon_{\mathrm{o}}
\end{array}\right] \text { for } \theta>\theta_{\mathrm{o}},
\end{gathered}
$$

where $Z(\sigma)$ is Zener-Hollomon's parameter, $\varepsilon_{\mathrm{o}}$ - stress dependent strain, $\theta$ - Dorn's parameter, $\theta_{0}$ - limit value of Dorn's parameter.

A simplified, but sufficiently accurate for fire engineering purposes, Bailey-Norton formula can replace the equation (1)

$$
\varepsilon=A(T, \dot{T}) \sigma^{n(T)}+\varepsilon_{T},
$$

and (2)

$$
\varepsilon=A^{*}(T, \dot{T}) \sigma^{n *(T)}+\varepsilon * T,
$$

where $A, n, A^{*}, n^{*}$ denote temperature dependent material functions, $\varepsilon_{T}, \varepsilon{ }_{T}^{*}$ - thermal strains.

\section{Identification of the model parameters}

\subsection{Idea of method}

Two stage method of identification [3] is applied for determination of the two pairs of parameters $A, n$ and $A^{*}, n^{*}$ from Bailey-Norton equations (3)-(4) that approximates the programmed non-linear constitutive relations (1) and (2). An application of that method requires:

1) generation of the set of the pair of value "stress $\sigma_{i}-\operatorname{strain} \varepsilon_{i}$ " calculated from constitutive equations (1) and (2),

2) assessment of the initial values of the parameters $A, n$ and $A^{*}, n^{*}$ by the linear least-squares method,

3 ) determination of final values of the parameters $A$, $n$ and $A^{*}, n^{*}$ using gradient method of MarquardtLevenberg $[8,5,2]$.

Details of the method are presented below.

\subsection{Generation of data sets}

For calculating parameters of Bailey-Norton relation as approximation of constitutive equations (1) and (2) two sets of basic values "stress $\sigma_{i}-$ strain $\varepsilon_{i}$ " are computed for two kinds of steel: ASTM A36 and A421. $N$ values of strains $\varepsilon_{i}$ are calculated from relation (1) or (2) for assumed stress values $\sigma_{i}$ (with limitation of computing to proper interval of strains).

Constitutive relation (1) and (2) are demanded competed identification of constants.

Properties of American steel ASTM A36 have been researched in Fire Research Station NRS. Harmathy and Stanzak $[4,6]$ have published results of tests.

The model (1) coefficients have been calculated by using the least-square method in [1] as characteristics dependent of temperature change $T$. Values of constants are defined by relations:

1) coefficient of linear expansion $\alpha\left[1 /{ }^{\circ} \mathrm{C}\right]$

$$
\alpha=a_{T} T+b_{T}=4.8136 \cdot 10^{-9} T+1,1928 \cdot 10^{-5},
$$

Table 1. Constants $a_{E}$ and $b_{E}$

\begin{tabular}{|c|c|c|}
\hline Interval of temperature $T\left[{ }^{\circ} \mathrm{C}\right]$ & $\begin{array}{c}a_{E} \\
{\left[\mathrm{MPa} /{ }^{\prime} \mathrm{C}\right]}\end{array}$ & $\begin{array}{c}b_{E} \\
{[\mathrm{MPa}]}\end{array}$ \\
\hline $20^{\circ} \mathrm{C}<T \leq 200^{\circ} \mathrm{C}$ & $-117,72$ & 208364 \\
\hline $200^{\circ} \mathrm{C}<T \leq 600^{\circ} \mathrm{C}$ & $-274,68$ & 239756 \\
\hline
\end{tabular}

2) modulus of elasticity $E[\mathrm{MPa}]$

$$
E=a_{E} T+b_{E},
$$

where constants $a_{E}$ and $b_{E}$ are given in Table 1 ,

Table 2. Constants $a_{\mu}, b_{\mu}, c_{\mu}$ and $d_{\mu}$

\begin{tabular}{|c|c|c|c|c|}
\hline $\begin{array}{c}\text { Interval of } \\
\text { temperature } \\
T\left[{ }^{\circ} \mathrm{C}\right]\end{array}$ & $\begin{array}{c}a_{\mu} \\
{\left[1 / /^{\circ} \mathrm{C}\right]}\end{array}$ & $b_{\mu}$ & $\begin{array}{c}c_{\mu} \\
{\left[1 /{ }^{\circ} \mathrm{C}\right]}\end{array}$ & $d_{\mu}$ \\
\hline $\begin{array}{c}20^{\circ} \mathrm{C}<T \\
\leq 200^{\circ} \mathrm{C}\end{array}$ & $-0,16489$ & 38,878 & 0 & 0 \\
\hline $\begin{array}{c}200{ }^{\circ} \mathrm{C}<T \\
\leq 591^{\circ} \mathrm{C}\end{array}$ & $-0,02479$ & 21,97 & $-0,3158$ & 186,65 \\
\hline $\begin{array}{c}591^{\circ} \mathrm{C}<T \\
\leq 600^{\circ} \mathrm{C}\end{array}$ & 1,5375 & $-901,32$ & 0 & 0 \\
\hline
\end{tabular}

3) coefficient of amplification $\mu$

$$
\mu=a_{\mu} T+b_{\mu}-\sqrt{c_{\mu} T+d_{\mu}},
$$

with constants $a_{\mu}, b_{\mu}, c_{\mu}$ and $d_{\mu}$ according to Table 2,

Table 3. Constants $a_{y}, b_{y}$ and $c_{y}$

\begin{tabular}{|c|c|c|c|}
\hline $\begin{array}{c}\text { Interval of temperature } \\
T\left[{ }^{\circ} \mathrm{C}\right]\end{array}$ & $\begin{array}{c}a_{y} \\
{[\mathrm{MPa}]}\end{array}$ & $\begin{array}{c}b_{y} \\
{\left[1 /{ }^{\circ} \mathrm{C}\right]}\end{array}$ & $c_{y}$ \\
\hline $20^{\circ} \mathrm{C}<T \leq 200^{\circ} \mathrm{C}$ & $304,11 \cdot 10^{-3}$ & 1,33 & 1026,52 \\
\hline $200^{\circ} \mathrm{C}<T \leq 600^{\circ} \mathrm{C}$ & $304,11 \cdot 10^{-4}$ & 9,47 & 9509,03 \\
\hline
\end{tabular}

4) yield point $\sigma_{y}[\mathrm{MPa}]$

$$
\sigma_{y}=a_{y}\left(b_{y} T+c_{y}\right)
$$

where constants $a_{y}, b_{y}$ and $c_{y}$ are given in Table 3 . 
They have been completed by values of:

a) coefficient $m=4,1883$,

b) quotient of activation energy and gas constant $\Delta H / R=38900$,

c) parameter $B=1,0543 \cdot 10^{-4}$.

The coefficients of model (2) have been calculated using the least-square method as characteristics dependent on temperature change $T$. Their values are defined by relations:

1) coefficient of linear expansion $\alpha^{*}\left[1 /{ }^{\circ} \mathrm{C}\right]$

$$
\alpha^{*}=a{ }^{*} T+b{ }^{*} T=4,8136 \cdot 10^{-9} T+1,1928 \cdot 10^{-5} \text {, }
$$

2) stress-dependent strain $\varepsilon_{o}$

$$
\varepsilon_{\mathrm{o}}=a_{\varepsilon_{\mathrm{o}}} \sigma^{b_{\varepsilon_{0}}}=9.262 \cdot 10^{-5} \sigma^{0.67},
$$

3) Zener-Hollomon's parameter $Z(\sigma)$

$$
Z(\sigma)=1,9518 \cdot 10^{8} \sigma^{3} \text { for } \sigma \leq 172 \mathrm{MPa},
$$

$Z(\sigma)=8,208 \cdot 10^{13} \exp (0,0145 \sigma)$ for $\sigma>172 \mathrm{MPa}$,

4) Dorn's parameter $\theta$

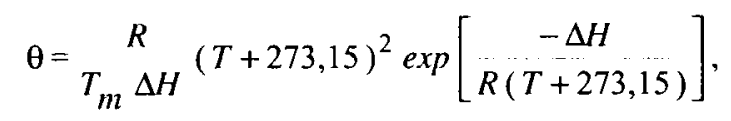

5) yield point $R_{m}[\mathrm{MPa}]$

$$
R_{m}=a_{R m}\left(b_{R m} T+c_{R m}\right),
$$

where constants $a_{R m}, b_{R m}$ and $c_{R m}$ are shown in Table 4, where quotient of activation energy and gas constant $\Delta H / R=30600$.

Table 4. Constants $a_{R m}, b_{R m}$ and $c_{R m}$

\begin{tabular}{|c|c|c|c|}
\hline $\begin{array}{c}\text { Interval of } \\
\text { temperature } T\left[{ }^{\circ} \mathrm{C}\right]\end{array}$ & $\begin{array}{c}a_{R m} \\
{[\mathrm{MPa}]}\end{array}$ & $\begin{array}{c}b_{r m} \\
{\left[1 /{ }^{\circ} \mathrm{C}\right]}\end{array}$ & $c_{R m}$ \\
\hline $20^{\circ} \mathrm{C}<T \leq 250^{\circ} \mathrm{C}$ & $1,72 \cdot 10^{3}$ & $-5,55550 \cdot 10^{-4}$ & 1,0111 \\
\hline $250^{\circ} \mathrm{C}<T \leq 600^{\circ} \mathrm{C}$ & $1,72 \cdot 10^{3}$ & $-2,02857 \cdot 10^{-3}$ & 1,3671 \\
\hline
\end{tabular}

In calculation the linear increase of temperature $T\left[{ }^{\circ} \mathrm{C}\right]$ has been assumed according to formula

$$
T=T_{m} t+T_{o},
$$

where ratio $T_{m}$ denotes velocity of temperature change, $T_{\mathrm{o}}$ - initial temperature.

Thermal strains are calculated from formulas

$$
\begin{gathered}
\varepsilon_{T}=\alpha T, \\
\varepsilon_{T}^{*}=\alpha^{*} T .
\end{gathered}
$$

\subsection{Determination of the initial parameters}

Linear least-square method is used to estimate initial values of Bailey-Norton model parameters based upon sets of "stress $\sigma_{i}-$ strain $\varepsilon_{i}$ " values for selected temperature levels $T$. The equation (3) can be described as relation

$$
\Delta \varepsilon_{i}=\varepsilon_{i}-\varepsilon_{T}=A \sigma^{n},
$$

and can be linearized by two-sided finding the logarithm

$$
\ln \Delta \varepsilon_{i}=n \ln \sigma_{i}+\ln A \text {. }
$$

Standard proceeding demanded the minimalisation of objective function in form sum of mean square deviations (where $x_{i}=\ln \sigma_{i}$ and $y_{i}=\ln \Delta \varepsilon_{i}$ are independent and dependent variables)

$$
Q=\sum_{i=1}^{N}\left(n x_{i}+\ln A-y_{i}\right)^{2}
$$

for $N$ finding the logarithm pairs of values " $\sigma_{i}-\varepsilon_{i}$ ". Calculation of derivates $\partial Q \partial n, \partial Q \partial(\ln A)$ and comparison to zero gives a system of equations which solution yields formulas of parameters $A$ and $n$ :

$$
A=\exp \begin{gathered}
\sum_{i=1}^{N} x_{i}^{2} \sum_{i=1}^{N} y_{i}-\sum_{i=1}^{N} x_{i} \sum_{i=1}^{N} x_{i} y_{i} \\
N \sum_{i=1}^{N} x_{i}^{2}-\left(\sum_{i=1}^{N} x_{i}\right)^{2}
\end{gathered}
$$

$$
n=\begin{aligned}
& N \sum_{i=1}^{N} x_{i} y_{i}-\sum_{i=1}^{N} x_{i} \sum_{i=1}^{N} y_{i} \\
& N \sum_{i=1}^{N} x_{i}^{2}-\left(\sum_{i=1}^{N} x_{i}\right)^{2}
\end{aligned}
$$

Identically are defined and calculated parameters $A^{*}, n^{*}$ of Bailey-Norton relation as a approximation of constitutive equation (2).

\subsection{Determination of the final parameters}

Proper estimation of parameters is realized in this stage with using gradient method of Marquardt-Levenberg $[8,5,2]$. This procedure requires iterative solution of matrix equation

$$
\left(\left[A^{*(k)}\right]+\lambda^{(k)}[I]\right) \delta^{*(k)}=\mathbf{g}^{*(k)},
$$

where $\left[\boldsymbol{A}^{*(k)}\right]$ is scaled main matrix obtained as a scaled product of gradient vector $[\boldsymbol{P}]$ for all $N$ data pairs of values $\left(\sigma_{i}, \varepsilon_{i}\right)$ from relations (1) or (2)

$$
\begin{aligned}
& {\left[\boldsymbol{A}^{*(k)}\right]=\left[a_{j j^{\prime}}^{*}\right]=\left[\frac{a_{j j^{\prime}}}{\sqrt{a_{j j}} \sqrt{a_{j^{\prime} j^{\prime}}}}\right],} \\
& {\left[\boldsymbol{A}^{(k)}\right]=\left[a_{j j^{\prime}}\right]=[\boldsymbol{P}]^{T}[\boldsymbol{P}],} \\
& {[\boldsymbol{P}]=\left[\begin{array}{c}
\partial f_{i} \\
\partial b_{j}^{(k)}
\end{array}\right], i=1,2, \ldots, N ; j=j^{\prime}=1,2 .}
\end{aligned}
$$

Constant $f_{i}$ is equal to strain $\varepsilon$ calculated from formula (1) (or (2)) for $i$ independent variable $\sigma_{i}$, but $b_{i}^{(k)}$ is estimated parameter $\left(b_{1}{ }^{(k)}=A, b_{2}{ }^{(k)}=n\right.$ for (1)). Derivates 
$\partial f_{i} \partial b_{j}^{(k)}$ are described by formulas

$$
\begin{gathered}
\partial f_{i} \\
\partial b_{1}^{(k)}
\end{gathered}=\sigma_{i}^{n},
$$

$$
\frac{\partial f_{i}}{\partial b_{2}^{(k)}}=A \sigma_{i}^{n} \ln \left(\sigma_{i}\right) .
$$

Matrix $\mathbf{g}^{*(k)}$ defines relations

$$
\begin{gathered}
\mathbf{g}^{*(k)}=\left[g_{j}^{*}\right]=\left[\frac{g_{j}}{\sqrt{a_{j j}}}\right], \\
\boldsymbol{g}^{(k)}=\left[g_{j}\right]=[\boldsymbol{P}]^{T}(\boldsymbol{\varepsilon}-\mathbf{f}),
\end{gathered}
$$

where $\boldsymbol{\varepsilon}, \mathbf{f}$ are vectors consisting of values $\varepsilon_{i}$ and strains calculated from formula (3) (or (4)) for variables $\sigma_{i}$. Scaled vector of correction $\delta^{*(k)}$ is determined from transformated equation (21)

$$
\delta^{*(k)}=\left(\left[\boldsymbol{A}^{*(k)}\right]+\lambda^{(k)}[\boldsymbol{I}]\right)^{-l} \mathbf{g}^{*(k)},
$$

where constant $\lambda^{(k)}$ multiplied by identity matrix $I$ modifies diagonal of matrix $\left[\boldsymbol{A}^{*(k)}\right]$.

Algorithm of Marquardt-Levenberg procedure requires „step by step" realization of calculations contained:

1) computation objective function $Q\left(\lambda^{(k-1=0)}=10^{-2}\right.$, $\left.\mathbf{b}^{(k-1=0)}\right)$ for initial values of parameter $\mathbf{b}^{(k-1=0)}$,

2) determination of gradient vector $[\boldsymbol{P}]$ and scaled main matrix [ $\boldsymbol{A}^{*(k)}$ ] from formulas (21),

3 ) calculation of scaled vector $\mathbf{g}^{*}(k)$ from relations (23),

4) computation scaled vector of correction $\delta^{*(k)}$ from (20) and normal ones $\delta^{(k)}$ described by formula

$$
\delta^{(k)}=\left[\delta_{j}\right]=\left[\frac{\delta_{j}^{*}}{\sqrt{a_{j j}}}\right],
$$

5) actualization of parameter vector $\mathbf{b}^{(k)}$

$$
\mathbf{b}^{(k)}=\mathbf{b}^{(k-1)}+\delta^{(k)},
$$

6) computation objective function $Q\left(\lambda^{(k)}, \mathbf{b}^{(k)}\right)$,

7) check the finish of calculation condition

$$
\begin{gathered}
\delta_{j} \\
\tau+b_{j}
\end{gathered} \leq \beta
$$

where constants $\tau=10^{-3}, \beta=10^{-5}$ and continuation computation for $(k=k+1)$ from point (2) (in case of no satisfy this condition).

Calculation steps (5) - (6) are realized for two constants $\lambda^{(k-1)}$ and $\lambda^{(k-1)} / 10$ which give two objective functions $Q\left(\lambda^{(k-1)}, \mathbf{b}^{(k)}\right)$ and $Q\left(\lambda^{(k-1)} / 10, \mathbf{b}^{(k)}\right)$. Depending on relation between these functions new value of $\lambda^{(k)}$ for iteration step $(k)$ is determined as equal:

a) $\lambda^{(k)}=\lambda^{(k-1)}$ when $Q\left(\lambda^{(k-1)}, \mathbf{b}^{(k)}\right) \leq Q\left(\lambda^{(k-1)}, \mathbf{b}^{(k-1)}\right)$,

b) $\lambda^{(k)}=\lambda^{(k-1)} / 10$ when $Q\left(\lambda^{(k-1)}, \mathbf{b}^{(k)}\right)>Q\left(\lambda^{(k-1)}\right.$, $\left.\mathbf{b}^{(k-1)}\right)$ and $Q\left(\lambda^{\left.(k-1) / 10, \mathbf{b}^{(k)}\right)} \leq Q\left(\lambda^{(k-1)}, \mathbf{b}^{(k-1)}\right)\right.$, c) $\lambda^{(k)}=10^{\xi} \lambda^{(k-1)}$ when $Q\left(\lambda^{(k-1) / 10} \mathbf{b}^{(k-1)}\right)>Q\left(\lambda^{(k-1)}\right.$, $\left.\mathbf{b}^{(k-1)}\right)$ and $Q\left(\lambda^{(k-1)} / 10, \mathbf{b}^{(k)}\right)>Q\left(\lambda^{(k-1)}, \mathbf{b}^{(k)}\right)$

(with $\xi=1,2 \ldots, \xi_{\text {max }}$ repetition until satisfying a condition).

This algorithm is used twice - first, for calculation pair of values $A, n$ and second - for specification $A^{*}, n^{*}$ (approximation of parameters for two different constitutive equations (1) and (2)).

\section{Modified method of forces}

\subsection{Idea of method}

For an analysis of the statically indeterminate space steel trusses, the modified method of forces $[1,2]$ is applied. The method considers approximation by equations (3)-(4) of non-linear constitutive relation (1) and (2) for steel. It is assumed that:

1) truss consists of steel bars (connected jointly in nodes) treated as one-dimensional elements,

2) fire simulates thermal forcing being, generally, an action of the temperature that increases linearly up to some level under an assumed rate of increment, individually, for a particular truss member,

3) static load in a form of the system of forces is applied to the joints,

4) all system and its particular components (struts) do not loose stability at elevated temperatures,

5) failure of the system occurs in case of exceeding a mean value of stress (in a section of any bar) that is limited by a yield stress at elevated temperatures,

6) prestress of string is simulated by assembly error which size is equal to shortening of string prestressed to stress level $\sigma=0,8 R_{m}\left(T=20^{\circ} \mathrm{C}\right)$,

Analysis of such defined problem by modified method of forces requires solution of the system of an algebraic non-linear equation:

$$
\mathbf{F}\left(\mathbf{X}^{(j)}\right)=\mathbf{0}
$$

where components of the vector of function $\mathbf{F}\left(\mathbf{X}^{(j)}\right)$ have a form

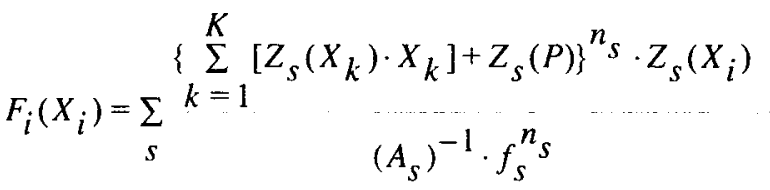

$$
\begin{aligned}
& l_{s}+\delta_{i T}+\delta_{i \Delta} \text {, } \\
& \delta_{i T}=\sum_{s}\left[Z_{s}\left(X_{i}\right) \varepsilon_{T} l_{s}\right], \\
& \delta_{i \Delta}=-\sum_{s}\left[Z_{s}\left(X_{i}\right) \Delta l_{s}\right] .
\end{aligned}
$$

The system of such equations is created routinely, by reduction of indeterminate truss system to determined one by means of selection of $K$ redundant forces $X_{i}$ and 
establishing forces $Z_{s}\left(X_{i}\right)$ and $Z_{s}(P)$ in bars for states $X_{i}=1$ and for external load $P$. Coefficients $\delta_{i T}$ are displacements along the direction of redundant $X_{i}$ induced by changes in temperatures $T$. Coefficients $\delta_{i \Delta}$ are displacements induced by assembly errors (shortenings of strings $\Delta l$ s prestressed to stress level $\sigma=0,8 \cdot R_{m}\left(T=20^{\circ} \mathrm{C}\right)$ ). Length $\mathrm{I}_{s}$ and area of section $\mathrm{f}_{s}$ characterize geometry of a bar or string. Constants $A_{s}, n_{s}$ and thermal deformation $\varepsilon_{T}$ define steel on every of the considered level of temperature $T$ under the rate of their increment.

\subsection{Algorithm of method}

Solution is achieved by calculation of an algorithm that requires:

I) identification of the parameters of Bailey-Norton model by two-stages method,

II) solution of the system of equation (28) in question using iteration Newton method by:

a) assignment of the forces $Z_{\mathrm{s}}$ in truss bars for states $X_{i}=1$ and for external load $\mathrm{P}$ and assessment of the initial values of the vector components redundant $\mathbf{X}^{(j)}$,

b) calculation of the vector of function $\mathbf{F}\left(\mathbf{X}^{(j)}\right)$ from relation (29) and matrix of derivatives $\mathbf{F}^{\prime}\left(\mathbf{X}^{(j)}\right)$ by means of finite difference method,

c) corrections of the redundant values according to the formula:

$$
\mathbf{X}^{(j+1)}=\left[\mathbf{F}\left(\mathbf{X}^{(j)}\right)\right]^{-1} \mathbf{F}\left(\mathbf{X}^{(j)}\right),
$$

d) checking of the condition of calculation interruption for all components of vector $\mathbf{F}\left(\mathbf{X}^{(j)}\right)$ (and in case of not satisfying the above condition - continuation of iteration from point (b))

$$
F_{i}\left(X_{i}^{(j)}\right) \leq \tau\left(\tau=10^{-4}\right),
$$

e) assignment of the real values of forces $Z_{s}$ in truss bars for determined vector $\mathbf{F}\left(\mathbf{X}^{(j)}\right)$,

III) checking of the failure condition of the truss structure according to the criterion of stresses

$$
\begin{aligned}
& -\sigma_{y}(T) \leq \sigma=\frac{Z_{s}}{f s} \leq \sigma_{y}(T), \\
& -R_{m}(T) \leq \sigma=\frac{Z_{s}}{f_{s}} \leq R_{m}(T) .
\end{aligned}
$$

\section{Set of computer programs}

Described algorithm is used by application made of a set of three integrated computer programs (Fig 1) that communicate by a common database.

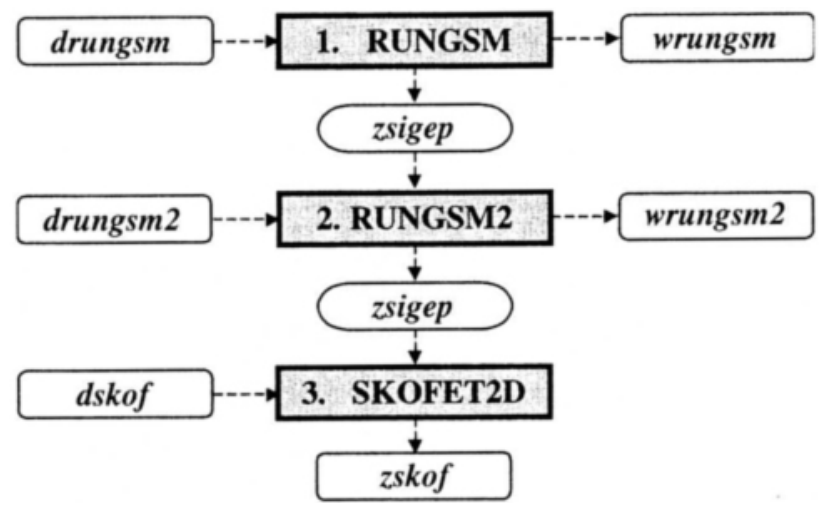

Fig 1. Structure of computer program set

All programs have been written in the FORTRAN 88 using double precision numbers in the calculation. The program RUNGSM realized identification parameters of Bailey-Norton formula (3) for steel ASTM A36. The calculation results are located in output data set zsigep (in form complete of 4 values: $A, n, \varepsilon_{T}$ and $\sigma_{y}$ ). The second program RUNGSM2 realized specification parameters of Bailey-Norton equation (4) for steel ASTM A421. The calculation results are located in the same output data set zsigep (in form complete of 4 values: $A^{*}$, $n *, \varepsilon^{*} T$ and $R_{m}$ ). Calculation according to presented algorithm of modified method of force is realised by the third program SKOFET2D, which final results located in output data wskof. Set drungsm, drungsm 2 and dskof are input data for these programs, but wrungsm, wrungsm 2 are output data (illustrating details of calculation).

\section{Numerical example}

One-time statically internally indeterminate system of plane prestressed steel truss (Fig 2) made of steel ASTM A36 and ASTM A421 (for string) was exposed to calculation analysis of thermal influences. All bars were made of pair angle bars. Areas of all horizontal bars and cross braces $K_{1}$ and symmetric equal to $f_{s}=69,6 \cdot 10^{-4} \mathrm{~m}^{2}$.

Areas of the other cross braces and truss posts are equal $f_{s}=45,4 \cdot 10^{-4} \mathrm{~m}^{2}$. Area of string ( 7 stranded wires) equals to $f_{s}=2,88901 \cdot 10^{-4} \mathrm{~m}^{2}$. This string was prestressed to stress level $\sigma=0,8 \sigma_{y}\left(T=20^{\circ} \mathrm{C}\right)=1,71998 \cdot 10^{6} \mathrm{kPa}$.

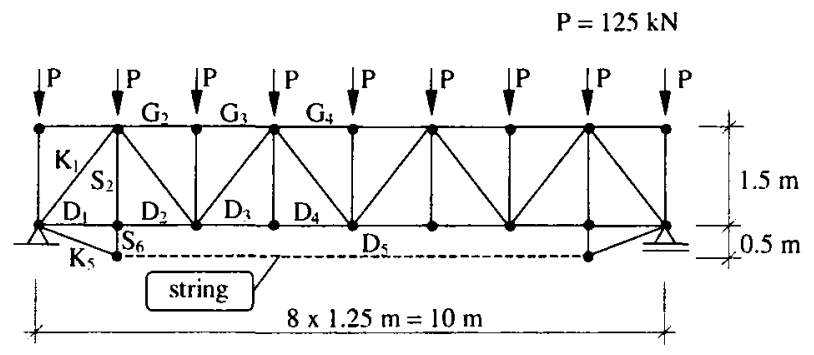

Fig 2. Plane prestressed steel truss

Upper joints of the structure are loaded by a set of 9 vertical concentrated forces $P=125 \mathrm{kN}$. Action of 

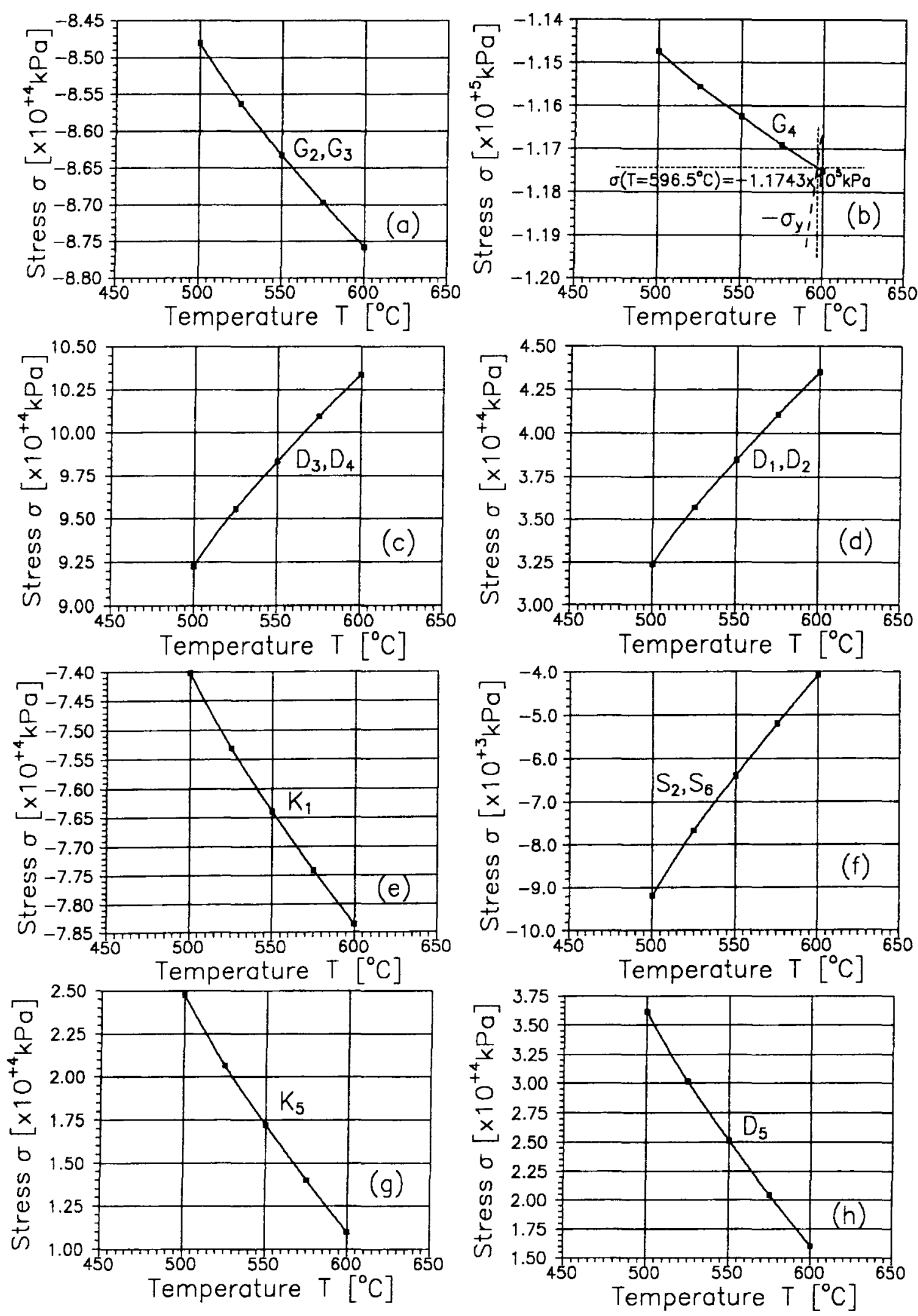

Fig 3. Distribution of stresses in chosen bars 
fire is simulated using rate of temperature change equal to $8{ }^{\circ} \mathrm{C} / \mathrm{min}$. Calculation was performed for 5 levels of temperatures $\mathrm{T}\left(500{ }^{\circ} \mathrm{C}, 525^{\circ} \mathrm{C}, 550^{\circ} \mathrm{C}, 575^{\circ} \mathrm{C}\right.$ and $\left.600^{\circ} \mathrm{C}\right)$.

Table 5. Parameters $A, n, e_{T}, s_{T}(T)$ for steel ASTM A36

\begin{tabular}{|c|c|c|c|c|}
\hline $\begin{array}{c}\text { Temperature } \\
T\left[{ }^{\circ} \mathrm{C}\right]\end{array}$ & $\begin{array}{c}A \\
{[1 / \mathrm{kPa}]}\end{array}$ & $n$ & $\begin{array}{c}\varepsilon_{T} \\
{\left[10^{-3}\right]}\end{array}$ & $\begin{array}{c}\sigma_{T}(T) \\
{\left[10^{5} \mathrm{kPa}\right]}\end{array}$ \\
\hline 500 & $2,06512 \cdot 10^{-21}$ & 3,26917 & 7,16740 & 1,45183 \\
\hline 525 & $1,90019 \cdot 10^{-21}$ & 3,67152 & 7,58895 & 1,37983 \\
\hline 550 & $1,76798 \cdot 10^{-21}$ & 3,71260 & 8,01651 & 1,30783 \\
\hline 575 & $1,6656] \cdot 10^{-21}$ & 3,75187 & 8,45010 & 1,23584 \\
\hline 600 & $1,70651 \cdot 10^{-21}$ & 3,77900 & 8,88970 & 1,16384 \\
\hline
\end{tabular}

Proper computation has been preceded by parameter identification of Bailey-Norton formula using twostage method. Calculation was performed by means of two programs RUNGSM and RUNGSM2 for 5 levels of temperatures $T$. Results of specification for both kinds of steel are presented in Tables 5, 6 .

The results of proper calculation for a chosen bars marked as in Fig 2 are presented in Fig 3 in a form characteristics "stress $\sigma$-temperature $T$ ". Calculation was performed by means of program SKOFET2D (according to algorithm modified method of forces) for 5 levels of temperatures $T$.

Failure of the truss with a string occurs as a result of exceeding, in bars $\mathrm{G}_{4}$ and symmetric, the criterion of stresses (33) at temperature $T=596,5^{\circ} \mathrm{C}$.

Table 6. Parameters $A^{*}, n^{*}, e^{*}, R_{m}(T)$ for steel ASTM A421

\begin{tabular}{|c|c|c|c|c|}
\hline $\begin{array}{c}\text { Temperature } \\
\left.T^{\circ} \mathrm{C}\right]\end{array}$ & $\begin{array}{c}A \\
{[1 / \mathrm{kPa}]}\end{array}$ & $n$ & $\begin{array}{c}\mathcal{E}^{*} T \\
{\left[10^{-3}\right]}\end{array}$ & $\begin{array}{c}R_{m}(T) \\
{\left[110^{5} \mathrm{kPa}\right]}\end{array}$ \\
\hline 500 & $1,26357 \cdot 10^{-21}$ & 3,21662 & 7,16740 & 1,45183 \\
\hline 525 & $1,70130 \cdot 10^{-17}$ & 2,70682 & 7,58895 & 1,37983 \\
\hline 550 & $3,30071 \cdot 10^{-14}$ & 2,34237 & 8,01651 & 1,30783 \\
\hline 575 & $2,15005 \cdot 10^{-14}$ & 2,25270 & 8,45010 & 1,23584 \\
\hline 600 & $5,84826 \cdot 10^{-15}$ & 2,43132 & 8,88970 & 1,16384 \\
\hline
\end{tabular}

\section{Conclusions}

The analysis performed indicates that it is possible to calculate precisely the fire resistance of steel trusses on the basis of:

(1) the known properties of steel at elevated temperature,

(2) the details of a cross-section dimensions, loaded shape of a construction,

(3) the data concerning the temperature increase in a construction, determined by the efficiency of the fireproof insulation.

The problem is important for people's safety.

\section{References}

1. Fedczuk P., Skowroński W. Effects of fire temperature changes on the flat steel truss. Scientific Collection (Zeszyty Naukowe), Vol 41, No 224/96, Opole: Technical University, 1996, p 109-121 (in Polish).

2. Fedczuk P., Skowroński W. Fire study of steel trusses in interacting systems of tall buildings. In: Proceedings of 5th International Conference on Tall Buildings, Vol 1, Hong Kong, 1998, p 1712-1732.

3. Skowronski W. Load capacity and creep problems of structural steelworks in fire. Study and Monography Z. 62, Opole: Technical University, 1992 (in Polish).

4. Plem E. Theoretical and experimental investigations of point set structures. Document D9, Stockholm: Swedish Council for Building Research, 1975.

5. Fedczuk P., Skowroński W. Two-stages method of parameter identification of Bailey-Norton model for fire heated structural steel. In: Scientific Collection (Zeszyty Naukowe), Vol 40, No 222/96, Opole: Technical University, 1996, p 5167 (in Polish)

6. Skowroński W. Buckling fire endurance of steel columns. Journal of Structural Engineering, Vol 119, No 6, 1993, p 1712-1732.

7. Skowroński W. Material characteristics in the analysis of heated steel beams. Fire and Materials, Vol 14, No 3, 1989 , p 107-116.

8. Marquardt D. W. An algorithm for least squares estimation of nonlinear parameters. J. Soc. Industr. Appl. Math, Vol 11, No 2, 1963, p 431-441. 